This is the peer reviewed version of the following article: Sandford, Stella (2017) Freud, Bion and Kant : epistemology and anthropology in The interpretation of dreams. International Journal of Psychoanalysis, 98(1), pp. 91-110., which has been published in final form at http://dx.doi.org/10.1111/1745-8315.12564. This article may be used for non-commercial purposes in accordance with Wiley Terms and Conditions for Self-Archiving. 


\section{Freud, Bion and Kant: Epistemology and Anthropology in The Interpretation of Dreams}

\section{Abstract}

This interdisciplinary article takes a philosophical approach to The Interpretation of Dreams, connecting Freud to one of the few philosophers with whom he sometimes identified - Immanuel Kant. It aims to show that Freud's theory of dreams has more in common with Bion's later thoughts on dreaming than is usually recognised. Distinguishing, via a discussion of Kant, between the conflicting 'epistemological' and 'anthropological' aspects of The Interpretation of Dreams, it shows that one specific contradiction in the book concerning the relation between dream-work and waking thought - can be understood in terms of the tension between these conflicting aspects. Freud reaches the explicit conclusion that the dream-work and waking thought differ from each other absolutely; but the implicit conclusion of The Interpretation of Dreams is quite the opposite. This article argues that the explicit conclusion is the result of the epistemological aspects of the book; the implicit conclusion, which brings Freud much closer to Bion, the result of the anthropological approach. Bringing philosophy and psychoanalysis together this paper thus argues for an interpretation of The Interpretation of Dreams that is in some ways at odds with the standard view of the book, while also suggesting that aspects of Kant's 'anthropological' works might legitimately be seen as a precursor of psychoanalysis. 


\section{Freud, Bion and Kant: Epistemology and Anthropology in The Interpretation of Dreams}

\section{Introduction}

Since the publication of Freud's The Interpretation of Dreams, there have been significant developments in the psychoanalytic understanding of the function and process of dreaming. In general, there has been a shift away from what commentators view as Freud's hermeneutical tendency to treat the dream as an object of study for the analyst, re-conceiving the process of dreaming as an integrated part of psychic life, or even the condition of possibility for aspects of mental functioning. For some it can seem that there is little theoretical or clinical profit to be gained from a renewed study of The Interpretation of Dreams, and recent analytic literature on dreaming is more likely to follow Bion than to examine the detail of Freud's arguments; Thomas Ogden $(1997,2005)$ exemplifies this tendency.

But if few analysts today are drawn to study The Interpretation of Dreams the same is not true of philosophers and other theorists in the humanities, over whom the book still exercises an abiding pull. Philosophers, especially, have been interested in the ways in which Freud's work provides an alternative approach to both some traditional and some more modern philosophical concerns, noting the ways in which Freud challenges various philosophical presuppositions and challenging him in turn. It thus seems that a gap has opened up between detailed textual interest in The Interpretation of Dreams (from philosophers and other theorists) and clinical interest in dreaming (from psychoanalysts). One would perhaps expect to find the 
crossing of this gap in the philosophically inflected psychoanalytic theory of, say, Jacques Lacan or Jean Laplanche; but this is not the case. ${ }^{1}$ Where the strongest claims are made concerning the philosophical radicality of psychoanalysis itself (for example Laplanche 1999, Van Haute 2005) The Interpretation of Dreams is never centre stage. (The Three Essays on The Theory of Sexuality is often the privileged text in this regard.)

In this essay I suggest that a philosophical approach to The Interpretation of Dreams, connecting Freud to one of the few philosophers with whom he sometimes identified, Immanuel Kant, shows that Freud's thinking on dreams has more in common with the later theories of Bion, in particular, than is usually recognised. Susana Vincour Fischbein and Beatriz Miramón have also recently argued in the IJP for the continuities between Freud's and Bion's 'conceptual models on dreams and dreaming', specifically in relation to their shared philosophical or 'epistemological' foundations. (2015: 1) In this article, however, I aim to demonstrate the continuities between Freud and Bion by distinguishing between the conflicting 'epistemological' and 'anthropological' aspects of The Interpretation of Dreams. In particular, I aim to show that one specific contradiction in The Interpretation of Dreams - concerning the relation between the dream-work and waking thought - can be understood in terms of the tension between these conflicting aspects. Freud, that is, reaches the explicit conclusion that the dream-work and waking thought differ from each other absolutely, but the

\footnotetext{
${ }^{1}$ Lacan does of course frequently refer to The Interpretation of Dreams, especially in the 1957 essay 'The Instance of the Letter in the Unconscious or Reason Since Freud' (in Lacan 2006), where he works through the relation between Freud's theory and structuralist linguistics. But his published works and his teaching (as far as we know) does not give The Interpretation of Dreams the same kind of sustained examination as other of Freud's works.
} 
implicit conclusion of The Interpretation of Dreams is quite the opposite. The explicit conclusion is the result of the epistemological aspects of the book; the implicit conclusion the result of the anthropological approach. In each case, I argue, it is via a discussion of aspects of Kant's philosophy that the stakes and the meaning of this tension are best explicated.

I begin with a discussion of Chapter I of The Interpretation of Dreams, showing how Freud appears to lead us to interpret the problem of dreams in Kantian epistemological terms and to distinguish sharply between dream-work and waking thought. I then turn to other Kantian sources that resonate more loudly with psychoanalytic concerns and more recent psychoanalytic thought on dreaming - Kant's 'anthropological' writings on dreams, fantasy and madness. Here, via a discussion of the function of the faculty of imagination, Kant argues against the sharp distinction between the process of dreaming and perception of reality. These claims, as I show, seem to be echoed in Bion's writings on dream-work- $\alpha$, and this is often taken to be the significant difference between Freud and Bion. The main point, however, that I wish to make is that this position on the intimate relation between dream-work and waking thought is already part of the 'anthropological' aspects of Freud's Interpretation of Dreams - a conclusion that Bion himself may well have reached, albeit he expressed it in different terms. It is, I argue, an overemphasis on the epistemological aspects of Freud dream book that has prevented many readers and commentators from seeing this. Bringing philosophy and psychoanalysis together, this paper thus argues for an interpretation of The Interpretation of Dreams that is in some ways at odds with the standard view of the book. But it does so in the hope of 
demonstrating the possibilities offered by the kind of interdisciplinary work of which Freud himself could be said to be a pioneer, while also suggesting that aspects of Kant's 'anthropological' works might legitimately be seen as a precursor of psychoanalysis.

\section{Dream image : waking reality}

Critics and sympathetic readers of Freud have often noted that his work relies on contradictory methodologies or models (Ricoeur 1970; Laplanche 1989) or argues for contradictory positions. In relation to The Interpretation of Dreams Meltzer, for example, claims that in almost every section of Chapter VI on the dream-work 'the theoretical statement that introduces the subsection is then refuted by the examples that follow.' (Meltzer 2009, 16) Nicholas Rand and Maria Torok (1997: 9-23) similarly see The Interpretation of Dreams as riven with unresolved contradictions. But contradictions are not only logical problems that mar theoretical endeavour; they are also (as both analysts and philosophers know well) interpretative opportunities. One egregious contradiction in Chapter VI of The Interpretations of Dreams presents us with a particularly good interpretative opportunity. Here Freud states, as one of the major conclusions of the book, something that contradicts - or at the very least is not indicated by - the whole of the preceding discussion. Having identified the four factors that constitute the specificity of the dream-work, Freud concludes, at the end of the discussion of secondary revision (one of those four factors), that the dream-work is not a more careless or irrational version of waking thought (as is suggested in some of the literature that Freud reviews), but that it is 'completely different from [waking thought] qualitatively 
and for that reason not immediately comparable with it.' (SE V, 507) ${ }^{2}$ There is nothing in the section on secondary revision (where this conclusion appears) and very little in anything that precedes it that warrants this conclusion; rather, almost everything suggests the opposite.

As I have already indicated, this contradiction can be understood as a result of the tension between two different approaches to the problem of dreams, which we may call 'epistemological' and 'anthropological', respectively. To demonstrate this, we need first to go back to Chapter I of The Interpretation of Dreams, 'The Scientific Literature Dealing with the Problem of Dreams', which appears to establish the problem of dreams in philosophical specifically epistemological - terms. Freud's survey of existing views begins with a Section entitled 'The Relation of Dreams to Waking Life'. In the form of a question, this topic is the hinge on which the whole book turns: what is the relation between dreams and waking life? This question is effectively equated with that of the relation between dreams and reality, implicitly equating 'waking life' with 'reality'. ${ }^{3}$ Freud then opens the second section of Chapter I with the identification of at least one point of agreement amongst all previous authors in relation to this question: 'All the material making up the content of a dream is in some way derived from experience, that is to say, has been reproduced or remembered in the dream - so much at least we may regard as an undisputed fact.' (SE IV, 11)

\footnotetext{
${ }^{2}$ Throughout page references refer to the Vintage edition of the Standard Edition of Freud's works.

${ }^{3}$ Given that affects in dreams (for example, fear) are 'real' in a way that the content of the dream that provokes them is not, Freud ends section $F$ of Chapter I by noting that 'we are faced by the problem of what part of the psychical processes occurring in dreams is to be regarded as real, that is to say, has a claim to be classed among the psychical processes of waking life.' (SE IV, 74)
} 
But what is the nature of the relation between the dream and the material from experience? Freud condenses the claims in the existing literature and finds them sharing one major one presumption: that the relation between dream and waking life is, more or less, that of the mechanical reproduction in a psychical register of external and internal organic, corporeal stimuli. This is the presumption, he shows, concerning both the immediate sources of the dream (sensory stimuli) and their mediation via memory; thus memory is effectively treated in the literature as sensory excitation at second hand. In all cases, Freud finds, the literature sees the registration of somatic events in the dream image; the literature presumes that there is a causal relation between somatic events and the production or reproduction of representations (Vorstellungen). Freud then identifies the same explanatory gap or deficit in all previous discussions of dreams. It is agreed that somatic stimuli, for example, appear in dreams in altered forms. But why does that happen? And what accounts for the precise nature of the alteration in the representation of the stimulus in the dream? What are the terms of the relation between stimulus and image? Freud finds no adequate answers to these questions in the existing literature.

With the addition of the problem of alteration (Veränderung), ${ }^{4}$ the question of the relation between dreams and waking life or between dreams and reality assumes a traditional, epistemological form. Epistemology - the philosophical study of what we can know and how we can know it; how objective knowledge is possible - classically asks: what is the relation

\footnotetext{
${ }^{4}$ See, for example, SE IV, 122. After the introduction of the idea of censorship in Chapter IV, the more neutral 'alteration' or 'change' (Veränderung) becomes the idea of 'distortion' (Entstellung) (Chapter IV is called 'Die Traumentstellung').
} 
between the representations in my mind and the external reality that they apparently represent? In The Interpretation of Dreams Freud asks: what is the relation between the dream representation and external reality? This is in fact remarkable. For to the extent that the epistemological question of the relation of both waking representation and dream representation to external reality is framed in the same way, Freud treats the dream representation as the epistemological analogue of the real, waking representation. He asks the question: 'what is the relation between dreaming and waking?' by treating the representations of dreaming and waking as having, epistemologically, the same relation to external reality.

Within this epistemological model, Freud arguably characterises all of his predecessors (even those closest to him) as naïve realists (that is, those who presuppose an unproblematic one-to-one causal relationship between 'reality' and representation, such that the epistemological problem of whether we do in fact know reality as it really is never arises). Freud convincingly demonstrates the inadequacy of the realist position for the interpretation of a dream. Indeed, as Bion writes, this scepticism concerning the presumptions of realism may be seen as fundamental to all psychoanalysis: 'psychoanalysis itself may be seen as born of a doubt about the realities of the knowledge we have, and of the processes by which we obtain it.' (Bion 1992, 151) ${ }^{5}$ However, the philosophical vocabulary and presuppositions of the German literature that Freud quotes in Chapter 1 of The Interpretation of Dreams are not naively realist; rather, they are strikingly Kantian. In fact, some version of Kant's

\footnotetext{
${ }^{5}$ See also Bion 1962, 48: 'I wish to emphasize that all that has been said about the problems of knowledge [in philosophy] applies with particular force to psycho-analysis and that psycho-analysis applies with particular force to these problems.'
} 
solution to the classic problem of epistemology seems to loom very large in both the literature that Freud discusses and in Freud's own novel contribution to the solution of the problem of the meaning of dreams. It is necessary to look a little more closely at this, in order to understand the consequences of this for Freud's explicit claims about the relation between dreaming and waking thought.

\section{The epistemological model}

It is not surprising to find traces of Kant's philosophy in the nineteenth-century German literature on dreams, given Kant's influence and the ubiquity of his ideas. These traces often appear to be a conscious adoption of Kantian ideas and terms, particularly from the Critique of Pure Reason, which concerns, in great part, the conditions for and limits of knowledge. Kant explained the basic epistemological problem that confronted him in a famous letter to Marcus Herz in 1772: 'What is the ground of the relation of that in us which we call “representation" [Vorstellung] to the object?' (Kant, 1772, 133) If it were the case that the object straightforwardly caused and determined the characteristics of the representation - which is the basic realist presumption the epistemological problem would dissolve, or not even arise in the first place. But of course the realist presumption is only a presumption, and it leaves us wondering whether things really are as they appear to us, or whether there is some alteration in the passage between object and representation that makes of the latter only a distorted or false representation of the former. This is the philosophical version of the suspicion that Bion sees as animating all psychoanalysis. If, on the other hand, it were the case that 
our representations brought the object into being - the idealist position - there would be no 'passage' in which alteration could lead to distortion. Its psychoanalytic equivalent is perhaps psychosis, or the inability to distinguish between phantasy and reality. Philosophically, idealism is unsatisfactory for all sorts of reasons, not least its need for a theological guarantee against subjectivism. For Kant the epistemological problem with both realism and idealism (traditionally understood) is the lack of any secure ground for the validity of judgements that are both necessarily true and non-trivial. We can be very confident about the universal validity of statements of logical identity or the validity of purely logical relations amongst statements, but these do not teach us anything about the world and they may have no relation at all to the objects of experience. Kant sought to ground the necessity of 'metaphysical' judgements about objects and the relations between objects, such as the judgement that 'every effect has a cause'.

Kant's answer to the problem was, of course, the doctrine of transcendental idealism. This proposes that knowledge is possible because the subject contributes a priori elements that give form and order to the sensory material acquired through the being-affected of the senses. The necessity of these a priori contributions of the faculties of sensibility and understanding grounds the objectivity of knowledge. The subject contributes the forms of space and time (the forms of intuition) and the a priori concepts or categories of the understanding, including the category of causality (hence the a priori contribution of the understanding grounds the metaphysical judgement 'every effect has a cause'). Because of this subjective contribution we know objects only as they appear to us, not as they are in themselves; but 
appearances (Erscheinungen) are empirically real, they are not mere semblance (Schein). The so-called transcendental unity of apperception - the transcendental necessity of the 'l' that must accompany all my representations - is another of the conditions of the possibility of knowledge and experience. The faculty of the imagination also plays a crucial role, not least in relating the faculties of understanding and sensibility. Thus transcendental idealism insists on the contribution of our own minds to the 'reality' that we cognise.

These aspects of Kant's theory of knowledge are frequently invoked in Chapter I of The Interpretation of Dreams, both in the way that Freud casts his questions and in the choice of the literature that he cites. Having identified the nub of the problem in the alteration undergone by the external stimulus in its representation in the dream Freud recasts the question of the relation between reality and dream representation: what, he asks, is the law or the rule of the conversion of the one into the other? (SE IV, 35, 37) According to Freud, any answer to this question will require us to posit something 'other than objective stimulus alone' (SE IV, 30), that is, it will require us to posit psychical sources for dreams. But Freud discovers that insofar as psychical sources of stimulation have been considered in the existing literature they have been downplayed, or they have once again been reduced, essentially, to somatic sources, and this reduction denies dreams the 'rank' or 'dignity' (Würde) of a 'psychical process'. (SE IV, 78)

The introduction of the idea of 'rank' or 'dignity' (that is, the introduction of a discourse of value, which might be thought to be foreign to epistemology) is interesting. In Section E, 'The Distinguishing Psychological Characteristic of 
Dreams', it becomes clear that the existing literature presumes that 'psychical processes' owe their dignity to their law-like character, while dreams are denied it because they are lawless. This is where the existing literature is most obviously Kantian, in one sense. Freud quotes Volkert speaking of 'the relaxing, disconnecting and confusing of ideational life, which in the waking state is held together by the logical force of the central ego [Ich]' (SE IV, 55). Scherner, too, notes 'how the centralized core of the ego - its spontaneous energy - [die Zentralität, die Spontanenergie des Ich] is deprived of its nervous force in dreams', and emphasises instead the liberation of the faculty of the imagination from the 'domination of reason' and from 'the hindrances of the categories of thought', with 'no concepts to exercise an attenuating influence.' (SE IV, 84) This point, and indeed the terminology, could be taken straight from Kant's Critique of Pure Reason. ${ }^{6}$ Freud goes on to quote Radestock: 'In fact it seems impossible to detect any fixed laws in this crazy activity.' (SE IV, 56) Paraphrasing Strümpell: 'there is an eclipse of all the logical operations of the mind which are based on relations and connections.' Paraphrasing Spitta: 'ideas that occur in dreams seem to be completely withdrawn from the law of causality'; all logical relations between ideas have disappeared, 'And so on, and so on', as Freud says (SE IV, 57). As the products of the mind, dreams are said to be hallucinations, or illusions (Illusionen). (SE IV, 58) Those familiar with Kantian philosophy (and we can

\footnotetext{
${ }^{6}$ Particularly from the sections on the synthesis of reproduction in the imagination and the second of the 'Analogies of Experience', where Kant discusses the objective law of appearances (basically: the law of causality) in distinction from the subjective sequences of perception, and where the 'subjective play of my imaginings', freed from the objective law of appearances, is indeed identified with 'a mere dream' (Kant 1781/87, A202/B247) References to Kant's Critique of Pure Reason cite the pagination of the first $(A)$ and second (B) German editions, as is conventional.
} 
assume that a great many of Freud's first Germanophone readers were) will recognise here a constant invocation of its terms.

To the extent that many of these authors presume some form of Kantianism, they seem to measure dreams against the processes - and the result - of cognition. The disparagement of dreams more or less equates with their being judged inadequate as forms of cognition, or in relation to cognition; the eulogising of dreams more or less equates with their being a delightful respite from cognition. From one perspective, then, we might sum things up as follows: Freud highlights the Kantian elements in the existing literature, selecting those passages in which the authors distinguish between dreams and waking life on the basis of the law-like and predictable nature of the latter. In dreams, on the other hand, there is a deficit of the understanding, leading to a cognitive deficit. The representations of waking life (appearances) are subject to constant rules supplied, a priori, by the understanding. If this were not the case waking life would be like a dream. As Kant put it, the empirical, and thus contingent, association of representations - for example, thinking of 'heavy cinnabar on the occasion of the representation of the colour red' would not be possible if cinnabar was not always red:

if cinnabar were now red, now black, now light, now heavy, if a human being were now changed into this animal shape, now into that one ... then my empirical imagination would never even get the opportunity to think of heavy cinnabar on the occasion of the representation of the colour red. (Kant 1781/87, A100-1)

In dreams, of course, this 'now one thing, now the other' is the 'rule'. 
If we follow this epistemological tendency in The Interpretation of Dreams, we would then see Freud distinguishing himself from his predecessors, not by opposing an anti-Kantianism to their Kantian presumptions, but by proposing an alternative set of rules or laws for dreams. If, for Freud, the mental processes of waking thought and of dreaming are distinct, this does not mean law-like processes for waking life and lawless processes for dreams, but rather different law-like processes for each. Following this epistemological interpretation one could then say that Freud did for dreams what Kant did for waking cognition: he uncovered the 'rules' of the relations between representations, albeit the 'rules', for Freud, are more properly considered as the processes of the dream-work. The Interpretation of Dreams can then, further, be seen as either committed to or instantiating a particular theory of knowledge, treating the dream as a particular kind of cognitive content, or its interpretation dealing with a particular cognitive problem.

Elsewhere, on more than one occasion, Freud compares himself to Kant or evokes Kant's philosophy in contexts that suggest that they share a common epistemology or at least a common epistemological problem. ${ }^{7}$ When commentators tend to see Freud's relation to Kant primarily through the prism of epistemology, in relation to Kant's Critique of Pure Reason, they thus follow Freud's own lead. ${ }^{8}$ It is this epistemological approach that leads Freud to separate off the dream as a peculiar object of knowledge and to distinguish, in

\footnotetext{
${ }^{7}$ For example in 1915, in the first section of 'The Unconscious' ('Justification for the Concept of the Unconscious'), SE XIV, 171. See also Bingswanger's reports of Freud's self-comparison with Kant in Tauber 2009, 4-7. Philosophers have often found the comparison convincing (for example Bergo 2004, 343-5; Sallis 2004, 1-4, 7, 9, 12-14).

${ }^{8}$ See Rockmore 2004, 22, 23, 31; Dreyfus 1976, xv-xvi; Sallis 2004.
} 
the conclusion to Chapter VI, so definitively between waking thought and the dream-work.

But other aspects of The Interpretation of Dreams evoke another set of Kant's writings: those on dreams, fantasy and madness. These mostly, but not exclusively, belong to what are broadly called Kant's 'anthropological' writings. Concentrating on these aspects The Interpretation of Dreams - as I will show in the following section - we get a rather different view of Freud's book, one in which the relation between dreaming and waking thought is rather less straightforward and which is more feasibly understood as the foundation of Bion's theory of dreaming rather than a rejected alternative to it. But to justify this claim we need to look first at the relevant claims in Kant's anthropology, in order to see how they reverberate with both Freud's and Bion's thinking on dreams and dreaming.

\section{The anthropological model}

Kant's anthropological works utilise the same a priori division of the 'faculties' or powers [Vermögen] of the mind (sensibility, understanding and reason) as the Critique of Pure Reason. But the focus of the anthropological works - and what perhaps makes them interesting for psychoanalysts - is more on the role of these faculties in dreaming and madness than on their 'proper' function in the construction of knowledge. What is particularly striking, though, is the relation between the 'proper' and the 'improper' states of the cognitive faculties. For Kant the failings or malfunctions of the cognitive faculties are, in some ways, an exaggeration of their 'proper' functions, a consequence of the strength of their idiomatic functioning, or a consequence of their 
independence from the other faculties. Furthermore, the discussion frequently invokes the dream as a mediating or ambiguous phenomenon between the proper and the improper functions of the faculties.

In Kant's Anthropology From a Pragmatic Point of View this is particularly the case with the faculty of imagination. The 'positive' aspect of the faculty of the imagination - its proper function - is almost indistinguishable from its errant aspect. In the context of the Critique of Pure Reason Kant calls the subjective play of the imagination without objective grounding 'a mere dream' (Kant 1781/87, A202/B247). In the context of the Anthropology its unmooring from any objective grounding is characterised both positively and negatively in terms of its capacity for invention. Invention governed by choice - such as that of artists - is called composition or fabrication; involuntary invention is called fantasy (Phantasie). 'We play with the imagination frequently and gladly', Kant writes, 'but imagination (as fantasy) plays just as frequently with us, and sometimes very inconveniently. ${ }^{, 9}$ The involuntary invention of images in sleep is called dreaming. The involuntary invention of images while awake, when imagination plays with us, is often said to be dreaming while awake. ${ }^{10}$

Later in the same book Kant offers us a slightly different and less elaborate empirical typology of forms of what he called, in an early (1764) anthropological essay, the 'maladies of the head'. Kant's terminology - in which he proposes names for types of mental malady and the kind of person afflicted by them - is not quite the same in the Anthropology and the 'Essay on the Maladies of the Head', but they agree in locating the nature of the

\footnotetext{
${ }^{9}$ Kant 1798 284, 285. See also 289.

${ }^{10}$ See, for example, Kant 1798, 285, 309.
} 
variously named maladies in relation to the functioning of the different faculties. In the 'Essay on the Maladies of the Head' Kant distinguishes between maladies of 'impotency' and maladies of 'reversal' (Verkehrtheit) (Kant 1764, 69). The former, which he calls 'imbecility', are physiological in origin and incurable; they do not interest him any further. His focus is the maladies of reversal, which he calls disturbances of the mind or the head and divides into three main types: dementia (Wahnsinn), insanity (Wahnwitz) and derangement (Verrückung). Each involves a 'reversal' in the function or the process of one of the mental capacities or faculties.

The most interesting case is the third of these: derangement. The deranged person takes an image for a perception, representing 'certain things as clearly sensed of which nevertheless nothing is present'. In derangement the problem is thus with 'the faculty that awakens the concepts in the soul', that is, sensibility - or more particularly the recollective part of sensibility (broadly understood) that is called imagination. (Kant 1764, 70-76) Kant's explanation for the appearance of derangement in the 'Essay on the Maladies of the Head' is tied to an account of dreams. The healthy mind of every human being, Kant says, is always occupied 'with painting all kinds of images of things that are not present'; the creative, poetic capacity of some human beings actually brings these images into sensation, that is, gives them material form. (Kant 1764, 70) This 'painting of images' is also characteristic of the sleeping mind, which is, for Kant the dreaming mind. In the Anthropology he says that we can take it as certain that there is no sleep without dreams; without dreaming sleep would be the same thing as dying, and anyone who says that they do not dream has merely forgotten their 
dreams. (Kant 1798, 297-8) In the 'Essay on the Maladies of the Head' Kant also writes this:

One has no cause at all to believe that in the state of being awake our mind follows other laws than in sleep. Rather it is to be conjectured that in the former case the lively sensible impressions only obscure and render unrecognisable the more chimerical images, while they possess their strength in sleep, in which the access to the soul is closed to all outer impressions. It is therefore no wonder that dreams are held for truthful experiences of actual things, as long as they last. Since they are then the strongest representations in the soul, they are in this state exactly what the sensations are in being awake. (Kant 1764, 70) As soon as we are awake we (usually, at least) see these chimeras for what they are. Even in that idle moment between sleeping and waking, when we gaze at the curtains or the wallpaper and sees human shapes in it, we are able to dispel this illusion the moment we want to. The deranged person, however, cannot dispel the illusion. They take their chimeras to be actual perceptual experiences: 'The deranged person is thus a dreamer in waking.' (Kant 1764, 71)

This idea is consistent through the 'Essay on the Maladies of the Head', the Critique of Pure Reason, the Anthropology, and indeed the Critique of the Power of Judgment. ${ }^{11}$ The crucial point in it, made most explicit in the Anthropology, is that derangement is facilitated by the fact of the 'analogy' between image and perception: 'the power of the imagination, which puts material under the understanding in order to provide content for its concepts

${ }^{11}$ See, for example, Kant 1781/87, B278; Kant 1790, 156. 
(for cognition) seems to provide a reality to its (invented) intuitions due to the analogy between them and real perceptions.' It is testament to the strength of the power of the imagination that 'a person sees and feels outside himself that which he has only in his mind'. (Kant 1798, 280, 288)

But it cannot be said that fantasies of the imagination are the result of the faculty 'failing'. ${ }^{12}$ Quite the contrary; the imagination is never more itself than under this free rein. As Monique David-Ménard says $(2000,85)$, it is merely a matter of a reversal in the balance of powers, imagination winning out over perception due either to the incapacities of the senses (in sleep) or because of the strength of the imagination itself. Moreover, the activity of the imagination is unceasing, the constant accompaniment of our sleeping state and of our waking perceptions of things that actually do exist. This being so, the activity of the imagination threatens constantly to overwhelm us when awake just as it does when we are asleep and dreaming. These dangers would not present themselves were it not the case that perception and imagination were inseparably intertwined, the latter (as empirical recollection) being necessary for the former. The imagination is a fundamental part of both functional perception at one end of a processual continuum and madness at the other. Imagination acts in exactly the same way in both. For Kant, the point of indifference between perception and fantasy is quickly reached, as the quotidian tendency for the imagination to impose itself is perfectly normal: 'this self-deception in sensations is very common ... human beings do not see through an ordinary delusion to what is there but rather what their inclination

\footnotetext{
12 Thus I cannot agree with Foucault $(1961,68-9)$ that the 'privileged domain' of the Anthropology is 'where they show their failings ... the movement by which the faculties, distancing themselves from their center and their justification, become other than themselves, illegitimate.'
} 
depicts for them: the natural history collector sees cities in Florentine stone, the devout person the passion in the speckled marble, some lady sees the shadow of two lovers on the moon in a telescope, but her pastor two church steeples.' (Kant 1764, 71-2)

Although derangement in all its forms involves the imaginative analogue of perception being taken for perception, Kant distinguishes between its mild and severe forms. In the mild case we call a person so afflicted a 'fantast' (Phantast); the hypochondriac is the most common example ('subject to illusory sensation of his own state'). The severe case is called, variously, the enthusiast (Schwärmer), the fanatic (Fanatiker) or the visionary (Visionär). This is 'a properly deranged person with presumed immediate inspiration and a great familiarity with the powers of the heavens. Human nature knows no more dangerous illusion.' (Kant 1764, 71, 72, 73) Kant's 1766 text Dreams of a Spirit-Seer Elucidated by Dreams of Metaphysics is a case history of a visionary: Emanuel Swedenborg. Here Kant distinguishes between the 'true' (sleeping) dreamer, the waking dreamer (the person absorbed in his own fantasies, who nevertheless can still distinguish between the fantasies 'inside' him and the objects of external perception) and the 'dreamers of sense' (Träumer der Empfindung), who, like Swedenborg, cannot distinguish between fantasy and reality. (Kant 1766, 329-30) Swedenborg's condition tallies with Kant's most general description of 'mental illness': 'the tendency to accept the play of ideas of inner sense as experiential cognition, although it is only a fiction', or, 'dreaming when awake' (Kant 1798, 272). Thus for Kant derangement, dream and waking perception 
are not three distinct psychical processes but three possible orders or three layers of sense, overlapping and bleeding into each other.

\section{Bion, dreaming, alpha function}

The fundamental difference between Kant's anthropological discussions of the place of dreams in mental life and the epistemological presumption of Freud himself (especially in Chapter I of The Interpretation of Dreams) concerns both the faculty thought to be responsible for the peculiarity of dreams and the state of that faculty in the process of dreaming. When, as is explicit in Kant's anthropological writings, the dream is the result of the specificity of imagination dreaming does not involve any special mental process; rather, some of the perfectly normal processes of the faculty, also at work in waking perception, come to the fore. The dream is the proper product of the imagination in its healthy functioning, not an improper by-product of its deficient state. On the other hand, when the peculiarity of the dream is approached as an epistemological problem, as with Freud's presentation of many of his Kantian predecessors, its peculiarity is attributed to a deficit or failure of the understanding (failure to supply the categories and so on). The anthropological position identifies the 'normal' reproductive function of the imagination as common and essential to both dreaming and waking perception, whereas the epistemological account of dreams that Freud extracts from the literature and his own epistemology of dreams posits a cut between them. In Kant's account the ostensible point of difference between dreaming and waking is that the 'deception of the senses', the illusion, in the dream is easily dispelled on waking; even so, the imagination does not cease 
to occupy itself 'with painting all kinds of images of things that are not present', as if the 'dream' is the constant imaginative companion of waking life, rendered 'obscure and unrecognisable' (Kant 1764,70$)$ by the vivacity of perception, but at work nevertheless. The distinction between dreaming and waking perception is held in the balance between them. But from an epistemological point of view, focused on the role of the logical functions of the understanding, the distinction between dreaming and waking perception is a qualitative one, a difference of mental process.

Pulling this together we see that the Kantianism of Freud's predecessors, at least as Freud presents them, and of a number of the recent commentators on the relation between Kant and Freud, betrays a prejudicial priority of epistemology, presuming that the essential question concerns the role of the faculty of the understanding. It also presumes the model of the knowing subject (or the balance of powers in the act of cognitive judgement) as the measure against which the dreaming subject is judged, isolating the dream as a determinate bounded phenomenon, cut off from waking perception, and constituting a specific epistemological object. In the anthropological model, on the other hand, the dreaming subject and the knowing subject are bound together through the function of the imagination. The ceaseless play of the imagination ensures that the knowing subject always also dreams while it knows and the distinction between dream, perception and derangement, although not dissoved, are certainly less clear than the epistemological model suggests.

The parallels between this 'anthropological' approach and aspects of Bion's theory of dreaming will no doubt have already struck many readers. 
Bion effectively expanded the scope of what counts as a 'dream' or as 'dreaming', and most particularly in insisting that one dreams while awake quite as much as while asleep: 'Freud says Aristotle states that a dream is the way the mind works in sleep: I say it is the way it works when awake'. (Bion $1992,43)$ Bion, as is well known, was peculiarly well versed in the history of Western philosophy and was particularly familiar with Kant's theory of knowledge, often referring to elements from The Critique of Pure Reason. The claim is often rightly made, further, that Bion's work is not just influenced by epistemology; it is itself partly philosophico-epistemological in nature. ${ }^{13}$ (See, for example Fischbein and Miramór 2015; Sandler 2006). But Bion's psychoanalytic epistemology is in fact a radical synthesis of what I have presented here as the 'epistemological' and 'anthropological' aspects of Kant's work. $^{14}$

This is most evident in Bion's notion of dream-work- $\alpha$, which appears to combine the epistemological function Kant assigned to the a priori aspects of the faculties of sensibility and understanding (giving form and intelligibility to the 'material' supplied by sensibility) and the 'anthropological' insight into the functions that cut across dreaming and waking thought: 'Dream-work- $\alpha$ is continuous night and day.' (Bion 1992, 63) Bion suggests that dream-work- $\alpha$ (or simply ' $\alpha$ ') 'ideogrammaticizes' 'impressions' (sometimes called $\beta$ - or betaelements) in a process of transformation that renders the impressions durable, and hence able to be stored and recalled, and able to be connected

\footnotetext{
${ }^{13}$ Bion's 'A Theory of Thinking' (in Bion 1967) is perhaps the best example of this.

${ }^{14}$ This is not to suggest that Bion knew Kant's anthropological work; sources suggest that he did not have these works in his library. (Noel Smith 2013, 125) Certainly he did not refer to them in his published works.
} 
to each other. (Bion 1992, 64, 67) This is not something other than conscious and unconscious rational thought; it is rather its condition of possibility. (Bion $1992,150,181)$ It is also the condition of possibility for 'dreaming' in the usual sense, referring to the sleeping dream. In Learning From Experience Bion sums it up thus: 'the "dream", together with the alpha-function, which makes dream possible, is central to the operation of consciousness and unconsciousness, on which ordered thought depends.' $(1962,16)$ At the same time, dream-work- $\alpha$ is also crucial to establish and maintain the differentiation between conscious and unconscious, the absence of which is characteristic of psychosis. Dream-work- $\alpha$ establishes a 'contact-barrier' which marks 'the point of contact and separation between conscious and unconscious elements and originates the distinction between them.' (Bion 1962, 17) Just like Kant's 'deranged' person, the person who lacks dream-work- $\alpha$ (and who thus cannot 'dream') struggles to distinguish between external and psychical reality, or to develop a 'sense of reality'. (Bion 1962, 42)

Bion's contribution here is enabled by a new approach to central aspects of Freud's theories, particularly as it allows him to think the crucial inter-relatedness and inter-dependency of functions or processes or aspects across the psyche. ${ }^{15}$ So for Bion 'the conscious and the unconscious thus constantly produced together do function as if they were binocular [and] therefore capable of correlation and self-regard.' (Bion 1962, 54) Further, 'dreaming' in the extended sense is a function that both unites and separates sleeping and waking and conscious and unconscious. In short, and cast

\footnotetext{
15 Thus I agree with Sandler (2006) and Fischbeing and Miramón (2015), contra Schneider (2010), that there is no 'paradigm shift' (Schneider 2010, 91) between Freud's and Bion's work on dreaming.
} 
explicitly in terms of a revision of Freud's theory of dreams, Bion asks: 'is it not possible that the mechanisms that Freud describes as peculiar to dream-work are in reality found to be operating over a wide area of the psyche and in a great number of different functional fields?' (Bion 1992, 138)

\section{Dream-work, day and night}

As I have tried to show, this possibility is already raised, mutatis mutandis, in Kant's anthropological work on dreams, fantasy and madness, which suggests that on this point Kant's anthropological work might legitimately bee seen as a precursor to psychoanalysis. But the main point that I want to make is that this possibility is also already part of Freud's theory of dreams, and that we may see this by distinguishing (on Kant's model) between the epistemological and 'anthropological' approaches within The Interpretation of Dreams. The contradiction between the explicit conclusion of Chapter VI that the dream-work is completely different from waking thought - and the opposite tendency of the thrust of most of the rest of the book is the result of the tension between these two approaches. Approaching the problem in epistemological terms Freud does indeed treat the dream-work as separate from waking thought. But the 'anthropological' approach that runs alongside the epistemological tendency actually presumes that the mechanisms of the dream-work are also operating continuously across all aspects of waking life too, opening the way for the idea that becomes explicit in Bion's work: the importance of the 'dream-work' to a whole range of psychic functions.

The justification for the claim that the expanded view of the dream-work is already part of Freud's theory of dreams must centre on his discussion of 
the dream-work itself in Chapter VI of The Interpretation of Dreams. Here Freud outlines the specific 'factors' (Momente) in the dream-work: i) the processes of displacement and condensation); ii) the need to avoid the censor; iii) considerations of representability (that is, the practical question of how ideas can be represented in displaced or condensed forms and the shift from verbal expression to 'thinking in images'); and iv) secondary revision. ${ }^{16}$ The discussion of the dream-work then often takes the form of statements about what it (in contrast with waking thought) does not and cannot do: it does not carry out any calculations; it does not create speeches; it does not actually perform any intellectual activity; it does not make any judgements; it cannot make an argument; it only translates dream thoughts according to the four previously identified factors in the construction of a dream. ${ }^{17}$ This follows on from claims in Chapter $V$ concerning the inability of the dream to express logical relations in its content (SE IV, 312), which is itself, for Freud, a consequence of the transformation in the mode of expression (there are, however, ways of expressing logical relations in the form of the dream, SE IV, $314-5)$. Freud's conclusion at the end of the section on secondary revision then emphasises the extent of the difference between normal waking thought and the dream-work. The factors that go to make up the dream-work are peculiar to dream-life and characteristic of it. This dream-work proper diverges further from our picture of waking thought than has been supposed even by the most determined depreciator of psychical

\footnotetext{
${ }^{16}$ Freud also often refers to overdetermination as one of the essential factors in the dream work, but to the extent that its mechanism is 'a transference and displacement of psychical intensities' (SE IV, 307), the formations to which overdetermination gives rise can be seen in terms of displacement (especially) and condensation.

17 See SE IV, 450-1, 445, 459, 545.
} 
functioning during the formation of dreams. It is not that it is more careless, more irrational, more forgetful and more incomplete than waking thought; it is completely different from it qualitatively and for that reason not immediately comparable with it. $(\mathrm{SE} \mathrm{V}, 507)^{18}$

This is the conclusion that seems so much at odds with Bion's work, for example. But surely the overwhelming tendency of The Interpretation of Dreams leads to the opposite conclusion. It can easily be demonstrated, with examples from Freud himself, that each of the four factors in the dream-work can be seen at work in waking thought too: in jokes, in the linguistic tricks of children [die Sprachkünste der Kinder]' (SE IV, 303), in parapraxes, literary forms and visual art, symptoms, and so on. To cite just one other work, The Psychopathology of Everyday Life contains a discussion of the process of displacement in misremembered names, even using the same image of a rebus or picture-puzzle $(\mathrm{SE} \mathrm{VI}, 5)$ used to characterise dreams in the earlier book. It also discusses the process of displacement in screen memories (SE $\mathrm{VI}, 43-5)$ and offers numerous examples of condensation in waking phenomena.

Within The Interpretation of Dreams, however, the case of secondary revision or elaboration (sekundäre Bearbeitung) is especially egregious. By identifying the factor of secondary revision the work of the censoring agency previously said to have only a defensive, and not a creative, relation to the dream (SE IV, 146) is now seen to take a part in its construction. (SE V, 489)

${ }^{18}$ Translation modified. Freud writes: 'Sie is nicht etwa nachlässiger, inkorrecter, vergeßlicher, unvollständiger als das wache Denken; sie is etwas davon qualitativ völlig Verschiedenes und darum zunächst nicht mit ihm vergleichbar.' (499) Strachey's translation of the first half of this sentence reads: 'The dream work is not simply more careless, more irrational, more forgetful and more incomplete than waking thought'; it softens Freud's point. 
Secondary revision (in The Interpretation of Dreams, at least) is definitely part of the dream-work, but introduced as a contribution to the content of the dream 'made by a psychical function which is indistinguishable from our waking thoughts.' (SE V 489) Freud writes that the function of secondary revision is the same as that 'which the poet maliciously ascribes to philosophers: it fills up the gaps in the dream-structure with shreds and patches', such that the dream 'approximates to the model of an intelligible experience' (SE V, 490) (thus this factor in dream construction is also sometimes characterised in terms of 'considerations of intelligibility'). Apparently logical and reasonable dreams 'have been subjected to a farreaching revision by this psychical function that is akin to waking thought'. (SE $V$, 490) A little later he says: 'There is no doubt, then, that it is our normal thinking that is the psychical agency which approaches the content of the dreams with a demand that it must be intelligible, which subjects it to a first interpretation and which consequently produces a complete misunderstanding of it.' Secondary revision is the contribution of 'normal thought' that gives the dream its 'final form'. (SE V, 500) Indeed: 'Our waking (preconscious) thinking behaves towards any perceptual material with which it meets in just the same way in which the function we are considering [secondary revision] behaves towards the elements of dreams. It is the nature of our waking thought to establish order in material of that kind, to set up relations in it and to make it conform to our expectations of an intelligible whole.' (SE V, 499) (The echo of this, mutatis mutandis, in Bion's 'alpha function' is easy to hear. ${ }^{19}$ ) In the later

\footnotetext{
${ }^{19}$ Which makes Meltzer's hostility to the concept somewhat puzzling. He calls secondary revision 'a shameful trick concept', used to 'caulk the whole leaky structure' of Freud's theory of dreams. (Meltzer 1984, 20)
} 
Totem and Taboo (1913) this tendency is identified with the construction of systems of thought - delusional structures, but also the 'normal' operation of a rational intellect: 'There is an intellectual function in us which demands unity, connection and intelligibility from any material, whether of perception or thought, that comes within its grasp; and if, as a result of special circumstances, it is unable to establish a true connection, it does not hesitate to fabricate a false one.' (SE XIII, 95)

Thus, by the end of Chapter VI, while the explicit conclusion distinguishes absolutely between dream-work and waking thought, the implicit conclusion, based on the discussion of secondary revision in particular, is exactly the opposite. This, as I have suggested, is the result of two competing approaches to the question. On the one hand, it is the epistemological approach in The Interpretation of Dreams that leads Freud to distinguish dreaming from waking thought so definitively. (Meltzer has already identified this approach as the root of the problems with Freud's theory of dreams. ${ }^{20}$ ) According to this model, waking thought is understood as normal cognition, whereas the dream-work is understood as its quasi-pathological other. The settling of this idea is marked towards the end of the book, particularly in Chapter VII, by the prominence of the new description of waking thought and dream-work as, respectively, 'normal mental activity' and 'abnormal processes of thought'. (SE V, 592, emphases added.) The dream thoughts are said to undergo 'a series of transformations which we can no longer recognise as normal psychical processes and which lead to a result that bewilders us - a

\footnotetext{
${ }^{20}$ See especially Chapter II, 'The Epistemological Problem in the Theory of Dreams', in Meltzer 2009.
} 
psychopathological structure.' (SE V, 595) $)^{21}$ The 'normal' and the 'abnormal' are 'two fundamentally different kinds of psychical process'. (SE V, 597) Freud saw it as a virtue of more recent work on dreams that it separated off the problem of dreams from that of sleep. Previously, he wrote in Chapter I, 'most writers on the subject have felt obliged to treat sleep and dreams as a single topic, and as a rule they have dealt in addition with analogous conditions on the fringe of pathology, and dream-like states, such as hallucinations, visions and so on.' (SE IV, 5-6) The distance produced by separating off the dream as a discrete object of knowledge, distinguishing it from related phenomena, is then not only echoed in the explicit result of the investigation, it produces this result: the psychical processes of the dreamwork are completely different from those of normal thought. This conclusion, unconvincing to and refuted by later psychoanalytic thinking on dreams, is the result of the epistemological approach in The Interpretation of Dreams.

On the other hand, to the extent that The Interpretation of Dreams echoes the anthropological approach, the dream-work remains embedded in the ebb and flow of everyday or 'normal' waking life. This suggests that the dream exhibits in exaggerated form aspects of the tendencies of waking life or 'normal' perception, to the extent that the latter is not a bald, flat, one-to-one correspondence between sense data and ideas but a complex process including what Kant identified as the necessary processes of the reproductive imagination. Or, if we insist that these processes (condensation, displacement, etc) are proper to dreams we should have to say that we do not cease to 'dream' when we wake - we do not cease to dream at all. This is not

${ }^{21}$ See also SE V, 596. 
to say that, in the ordinary course of events, we cannot distinguish between dreaming and waking thought; but it is to say - as Bion would later make explicit - that normal 'waking thought' has an oneiric lining.

It is also not at odds with the fundamental topographical theory of the psychical apparatus elaborated in Chapter VII of The Interpretation of Dreams. The picture of the psychical apparatus at which Freud arrives in Chapter VII is that of a 'reflex apparatus' 'compounded of $\Psi$-systems' and moving from the direction of stimulus (Pcpt.) to (motor) discharge. (SE V, 537) Within these systems the motive for the construction of dreams is located in the system Ucs. According to Freud: 'If we describe as "progressive" the direction taken by psychical processes arising from the unconscious during waking life, then we may speak of dreams as having a "regressive" character.' (SE V, 542) The excitation from system Ucs. moves not forwards into Pcs. but backwards to Pcpt., such that dreams are described as the hallucinatory revival of perceptual images. Stressing that in both dreams and visions we 'attach belief' to the hallucinatory image (SE V, 535), Freud agrees completely with Kant's view of dreams and visions. Although Freud warns us against taking his spatial picture of the psychical apparatus literally, we follow his lead if we ask 'where' in it the dream-work happens. The answer must be: in system Ucs. If we say, therefore, that the 'dream-work' is as much a part of waking life as of the sleeping dream, we say no more than that unconscious psychical processes are at work in waking thought. And where is the analyst who would disagree with that? It remains true that, except in the psychoses, we can and must distinguish between dreams and waking reality; but this does not means that what is characteristic of the dream-work is alien to 
waking life, even if it is alien to consciousness. This is the 'anthropological' insight from The Interpretation of Dreams upon which Bion builds.

Of course, one major difference between Bion's theory of dreaming and the received view of Freud's theory still remains. This concerns the function attributed to dreaming, and is often identified as the most significant point of divergence between the two thinkers (Meltzer 2009, Schneider 2010). Whereas Freud specified the function of dreams as being 'the guardians of sleep' (SE V, 678), necessitating the disguise of ideationa/ material through the dream-work, Bion suggests that dreaming is the fundamental way in which we process our emotional experience. And certainly it is true that the idea of dreaming as such emotional processing does not ever seem to have been part of Freud's explicit thinking. But it is also true that there seems to be an overemphasis on the question of function in the received view of Freud's theory of dreams, which eclipses the richer aspects of The Interpretation of Dreams. The functions Bion ascribes to dreaming and dream-work $\alpha$ is a development of these richer aspects of Freud's own work, or as Bion himself put it: 'a legitimate extension of an opening for investigation which Freud made but did not follow up.' (Bion 1962, 73)

\section{References}

Bergo, B (2004). Freud's Debt to Philosophy and his Copernican Revolution. In J Radden, ed. The Philosophy of Psychoanalysis: A Companion. Oxford: Oxford University Press. 
Bion, WR (1962). Learning From Experience. London: Karnac.

Bion, WR (1967). Second Thoughts. London: Karnac.

Bion, WR (1992). Cogitations. London: Karnac.

David-Ménard, M (2000). Kant's 'An Essay on the Maladies of the Mind' and Observations on the Feeling of the Beautiful and the Sublime, trans. A Ross. In Hypatia, 15: 4 (Fall), 82-98.

Dreyfus, H (1976) Foreword to M. Foucault, Mental Illness and Psychology, trans. A Sheridan. Berkeley etc: University of California Press.

Fischbein, SV \& B Miramón (2015). Theoretical Trajectories: Dreams and dreaming from Freud to Bion. IJP 96 (4): 967-992.

Foucault, M (1961). Introduction to Kant's Anthropology, trans. R Nigro and K Briggs. Los Angeles CA: Semiotext(e), 2008.

Freud S (1900). Die Traumdeutung. Frankfurt am Main: Fischer Taschenbuch Verlag (2007).

Freud S (1900). The Interpretation of Dreams. SE IV \& SE V. 
Freud S (1901). The Psychopathology of Everyday Life. SE VI.

Freud S (1913). Totem and Taboo. SE XIII, p. ix-162.

Freud S (1915). The Unconscious. SE XIV, p. 159-215.

Kant, I (1764). Essay on the Maladies of the Head, trans. H. Wilson. In G

Zöller and RB Louden, eds. Anthropology, History, and Education (Cambridge

Edition of the Works of Immanuel Kant). Cambridge: Cambridge University Press, 2007.

Kant, I (1766). Dreams of a Spirit-Seer Elucidated by Dreams of Metaphysics, trans. D Walford In D Walford and R Meerbote, eds., Theoretical Philosophy 1755-1770 (The Cambridge Edition of the Works of Emmanuel Kant). Cambridge: Cambridge University Press, 2002.

Kant, I (1772). Letter to Marcus Herz, February 21 1772. In: A Zweig, ed. and trans. Correspondence. Cambridge: Cambridge University Press, 1999.

Kant, I (1781/87) Critique of Pure Reason. P Guyer and AW Wood trans. Cambridge: Cambridge University Press, 1998.

Kant, I (1790). Critique of the Power of Judgment, trans. PGuyer and E Matthews. Cambridge: Cambridge University Press, 2000. 
Kant, I (1798). Anthropology from a Pragmatic Point of View, trans. Robert B Louden. In G Zöller and RB Louden, eds. Anthropology, History, and Education (Cambridge Edition of the Works of Immanuel Kant). Cambridge: Cambridge University Press, 2007.

Lacan, J (2006) Écrits, trans. B Fink. New York \& London: Norton.

Laplanche, J and J-B Pontalis. (1988) The Language of Psychoanalysis, trans. D Nicholson-Smith. London: Karnac and The Institute of Psychoanalysis.

Laplanche, J (1989) New Foundations for Psychoanalysis, trans. D Macey. Oxford: Blackwell.

Laplanche, J (1999) The Unfinished Copernican Revolution, trans. Luke Thurston. In Essays on Otherness. London \& New York: Routledge.

Meltzer, D (2009). Dream Life: A Re-examination of the Psychoanalytic Theory and Technique. London: Karnac.

Noel-Smith, K (2013) Thoughts, thinking and the thinker: Bion's philosophical encounter with Kant. In N Torres \& RD Hinshelwood, Bion's Sources: The Shaping of his Paradigms. Hove, E Sussex and New York: Routledge. 
Ogden, T (1997). Reverie and Interpretation: Sensing Something Human. New Jersey \& London: Jason Aronson.

Ogden, T (2005). This Art of Psychoanalysis: Dreaming Undreamt Dreams and Interrupted Cries. London and NY: Routledge.

Rand, N and M Torok. (1997) Questions for Freud: The Secret History of Psychoanalysis. Cambridge MA and London: Harvard University Press.

Ricoeur, P (1970) Freud and Philosophy: An Essay on Interpretation, trans. Denis Savage. New Haven \& London: Yale University Press.

Rockmore, T (2004). Freud's Dream Theory and Social Constructivism. In J Mills. ed. Rereading Freud: Psychoanalysis Through Philosophy. New York: SUNY Press.

Sallis, J (2004). The Logic and Illogic of the Dream-Work. In Mills, ed. Rereading Freud: Psychoanalysis Through Philosophy. New York: SUNY Press.

Sandler, P C (2006). The Origins of Bion's work. IJP 87: 179-201.

Schneider, JA (2010). From Freud's dream-work to Bion's work of dreaming: The changing conception of dreaming in psychoanalytic theory. IJP 91: 521540. 
Tauber, A I (2009) Freud's Dream of Reason: The Kantian Structure of

Psychoanalysis. History of the Human Sciences 22(4), 1-29.

Van Haute, P (2005). Psychoanalysis And/As Philosophy? The Anthroplogical

Significance of Pathology in Freud's Three Essays on the Theory of Sexuality.

Natureza Humana 7(2): 359-374. 